\title{
Technical Accuracy of Dental Laboratories in the Quality and Shade Matching of Porcelain Fused to Metal Crowns: An In Vitro Study
}

\author{
Mohammed. S. Bin-Shuwaish ${ }^{1}$, Yasser F. AlFawaz ${ }^{1}$, Hamad A. AlGamaiah ${ }^{1}$, Abdulaziz S. AlSani ${ }^{2}$, \\ Ibrahim B. Abobakr ${ }^{1}$, Khaled M. Alzahrani ${ }^{3}$, Basil Almutairi ${ }^{1}$, Esraa A. Attar ${ }^{4}$, Fahim Vohra ${ }^{5}$ (D) \\ and Tariq Abduljabbar $5, *$ D
}

Citation: Bin-Shuwaish, M.S.; AlFawaz, Y.F.; AlGamaiah, H.A.; AlSani, A.S.; Abobakr, I.B.; Alzahrani, K.M.; Almutairi, B.; Attar, E.A.; Vohra, F.; Abduljabbar,

T. Technical Accuracy of Dental

Laboratories in the Quality and Shade Matching of Porcelain Fused to Metal Crowns: An In Vitro Study. Int. J. Environ. Res. Public Health 2021, 18, 2722. https://doi.org/10.3390/ ijerph18052722

Academic Editor: Daisuke Ekuni

Received: 16 February 2021

Accepted: 4 March 2021

Published: 8 March 2021

Publisher's Note: MDPI stays neutral with regard to jurisdictional claims in published maps and institutional affiliations.

Copyright: (C) 2021 by the authors Licensee MDPI, Basel, Switzerland. This article is an open access article distributed under the terms and conditions of the Creative Commons Attribution (CC BY) license (https:// creativecommons.org/licenses/by/ $4.0 /)$
1 Department of Restorative Dental Sciences, College of Dentistry, King Saud University, 60169, Riyadh 11545, Saudi Arabia; malshowaish@ksu.edu.sa (M.S.B.-S.); yalfawaz@ksu.edu.sa (Y.F.A.); algamaiah@gmail.com (H.A.A.); ibabakr@gmail.com (I.B.A.); balmutiri@ksu.edu.sa (B.A.)

2 Graduate Restorative, School of dentistry, University of Michigan, Ann Arbor, MI 48109, USA; assani@gmail.com

3 Department of Prosthetic Dental Sciences, College of Dentistry, Prince Sattam Bin AbdulAziz University, Alkharj 11942, Saudi Arabia; dr_kmq@hotmail.com

4 Oral and Maxillofacial Prosthodontics Department, Faculty of Dentistry, King AbdulAziz University, Jeddah 21589, Saudi Arabia; eaattar@kau.edu.sa

5 Department of Prosthetic Dental Science, College of Dentistry, King Saud University, Research Chair for Bio-logical Research in Dental Health, Riyadh 11545, Saudi Arabia; fvohra@ksu.edu.sa

* Correspondence: tajabbar@ksu.edu.sa; Tel.: +966-01344555

Abstract: Dental laboratories (LABs) are integral to the performance of a dentist in providing successful oral rehabilitation. The aim of this study was to compare the adaptation, contour, contacts, and shade matching of different government and commercial dental LABs in the fabrication of porcelain fused to metal (PFM) crowns. Thirty-two dental LABs were selected to fabricate PFM crowns (one PFM crown each). Marginal adaptation, contour, proximal contacts, and shade matching were evaluated. Evaluation of the crowns' quality was performed following modified USPHS/FDI criteria. Visual and colorimeter assessments were employed to evaluate shade matching. Differences between groups were examined by Pearson's Chi-square and Fisher's exact test. The quality of marginal adaptation of crowns was good in $81.25 \%$, however the quality of contours, contacts, and shade matching was compromised in $43.75 \%, 59.38 \%$, and $39 \%$ of all LABs, respectively. Visual and colorimeter shade matching was acceptable in $62.5 \%$ and $80 \%$ of LABs in the cervical third and middle third regions of crowns, respectively, however in the incisal third the shade matching was unacceptable in nearly $60 \%$ of LABs. Commercial laboratories showed significantly better contours and shade matching, but not marginal adaptation. However, no significant differences were found in comparison of proximal contacts between the groups.

Keywords: work quality; laboratories; crowns; dental; technician; shade matching; adaptation

\section{Introduction}

Oral rehabilitation commonly involves provision of dental prosthesis fitted by dentists and fabricated by laboratory (LAB) technicians. However, nearly $4 \%$ of all the restorations made in laboratories are returned by clinicians for remaking [1]. The quality of the prostheses generated by a dental laboratory is greatly dependent on the knowledge and experience of both parties, their attention to detail, and the equipment used [2-5]. Individual possible factors which may render a crown unacceptable include poor impressions, lack of occlusal and axial reduction, poor mounting, inaccurate inter-occlusal record, and poor laboratory work. The successful rehabilitation of teeth by means of prosthetic devices requires meticulous teamwork and communication between the dentist and the 
dental laboratory technicians. Therefore, a clear prescription from the clinician can prevent unnecessary remakes, delays, and/or pre-insertion adjustments [6]. Although it is possible to reproduce the natural characteristics of dental tissue with dental porcelain, esthetic excellence, particularly the color matching of a porcelain restoration to natural dentition or existing restoration, is a challenging task $[7,8]$.

An acceptable and clinically successful restoration must display adequate fit and adaptation, shape and contours, esthetic appearance with shade matching, and suitable hygienic contacts. Poor fit and adaptation lead to micro leakage and secondary caries, however shape and contour errors cause asymmetry and plaque accumulation [9-11]. Fabrication of acceptable esthetic restoration requires the integration of several critical factors, including an individual's perception of color and the environment during visual shade selection, knowledge of dental anatomy, compatibility with materials, preparation designs, and accurate impressions [12,13]. In dentistry, porcelain fused to metal (PFM) crowns are the most commonly indicated in oral rehabilitations, however the challenge for shade matching in PFM crowns is high due to the metal substructure [14]. In addition, the metal copings for PFM restorations are fabricated with variable techniques, including casting, subtractive manufacturing or milling and additive manufacturing or 3-D printing. Furthermore, the opaque metal substructure is veneered with conventional and contemporary ceramic technologies, such as sintering, computer-aided design, computer-aided manufacturing, and heat pressing [11]. Therefore, the different complex fabrication procedures make PFM restorations particularly prone to color and fit inaccuracies. It is suggested that the color differences within and among commercially available dental ceramics may contribute to errors in the shade duplication process [15-17]. However, continued research has incorporated virtual technology and digital color measurement systems into clinical dentistry, to avoid the variability of conventional visual shade selection procedures [18]. Among the contemporary systems for shade matching, ShadeEye-NCC is a device that provides intraoral readings with four porcelain systems (Vita 3D-Master, Vitapan Classical, Vintage Halo, and Biodent) in clinical use and along with CIE $\mathrm{L}^{*} \mathrm{a}^{*} \mathrm{~b}^{*}$ coordinates. The system allows registration of direct color coordinate specifications without the use of mathematic manipulation. The system is designed to measure the shades of natural teeth or restorations through a disposable flat contact tip measuring $2.5 \mathrm{~mm}$ in diameter [19].

A dentist prepares teeth and the impression of the tooth designated for restoration. It is primarily the technician's skills and judgment that are responsible for the production of a clinically acceptable restoration. Therefore, the knowledge and skills of the laboratory technician are highly critical in producing a successful restoration [5,6]. In a recent study by Jathmi et al., 70\% of cases fabricated by LAB technicians were able to duplicate the shade accurately as determined by spectrophotometer [20]. In a similar study by Alshiddi et al. variations in the accuracy of indirect restorations made by laboratories managed by dental schools and those privately managed were assessed [21]. They reported wide variations in the accuracy and standards of restorations, and overall found no significant difference in restorative quality among privately and state-run LABs. However they failed to report the esthetic, contours, and contact parameters critical for the success of PFM restorations. To our knowledge from indexed literature, there are few research reports showing the accuracy of dental laboratories for fitting, contouring, contacting, and shade matching of dental crowns. It is hypothesized that there is no difference among laboratories (government and commercial) in the fabrication of high-quality and shade-matched PFM crowns. Therefore, the aim of this study was to assess and compare the accuracy of different dental laboratories (commercial and government) in the fabrication of high-quality and esthetic porcelain fused to metal (PFM) restorations.

\section{Materials and Methods}

In this in vitro cross-sectional study, 32 dental laboratories (16 government and 16 commercial) were included. The LABs were randomly selected but equally divided into commercial and government. Government LABs were from health sectors, as well as dental 
school-based laboratories. The study was performed at the College of Dentistry, King Saud University, from Jan 2019 to May 2019. Figure 1 presents the processes performed in the study as a flow diagram.
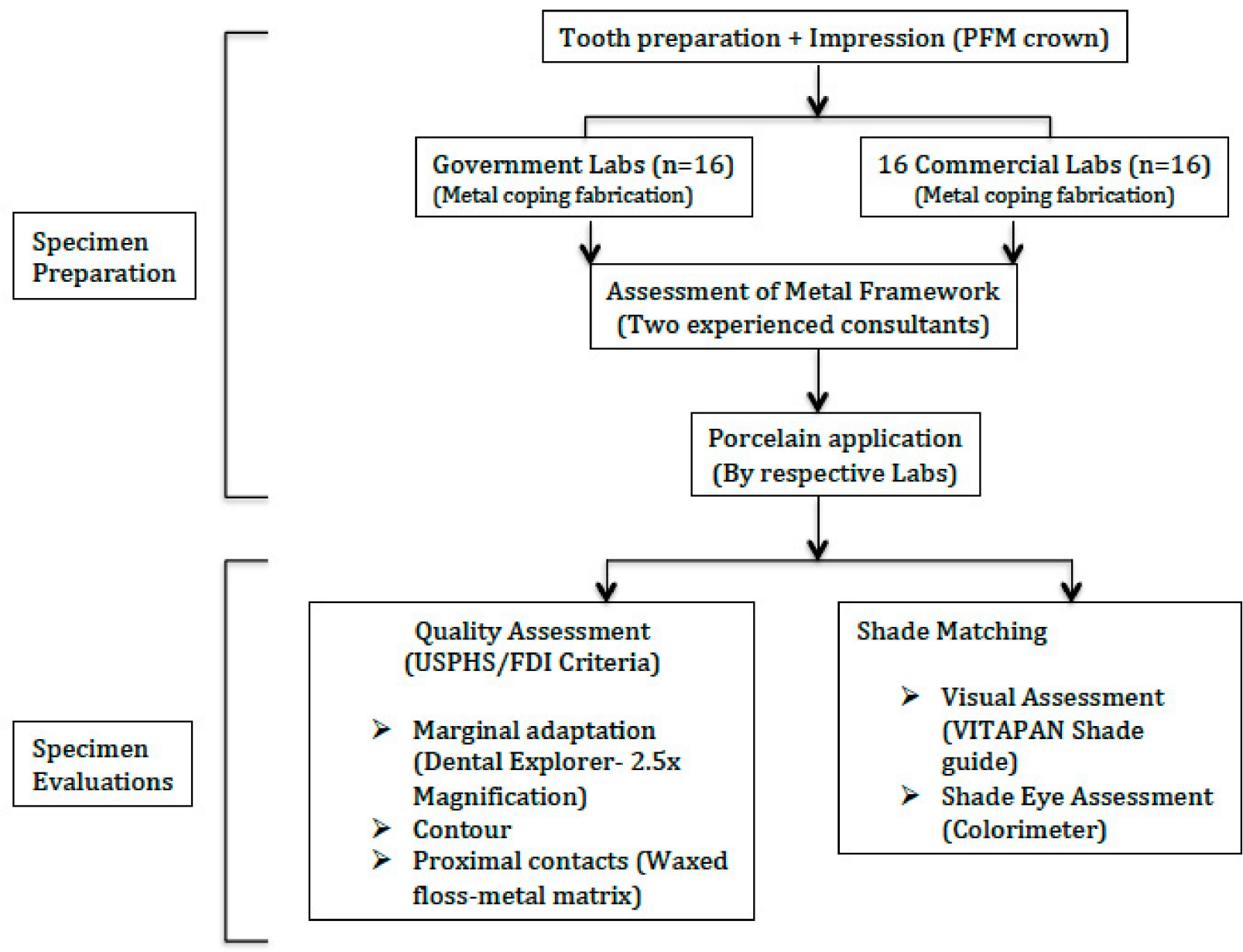

Figure 1. Flow diagram of the study methods.

\subsection{Specimen Preparation}

Tooth preparation for a PFM crown on a maxillary left central incisor (Ivorine tooth \#21), mounted on a dentoform jaw model (NISSIN Dental Products Inc., Kyoto, Japan), was performed using an index having reductions of $1.5 \mathrm{~mm}$ facial (2 plane), $1.0 \mathrm{~mm}$ palatal, and $2.0 \mathrm{~mm}$ incisal, with facial shoulder margins and palatal chamfer margins. The prepared tooth \#21 in the dentoform jaw model was then unscrewed and fitted into the socket-like hole for tooth \#21 on a study cast model for a simulated patient. The prepared Ivorine tooth was secured on the study cast. Thirty-two final impressions, in a light- and heavy-body polyvinyl siloxane impression material (Aquasil, Dentsply, York, PA, USA), in plastic full-arch trays were taken for the master cast by a senior clinician (MSB). Quality of the impressions was carefully inspected by means of a $2.5 \times$ magnification loupe. Final impressions were sent to the laboratories on the same day as they were recorded, along with the opposing casts and bite records (Occlufast, Zhermack, Italy). A standard work authorization form was prepared, including impression pouring into a die stone for fabrication of a working cast model, pindexing, die trimming, waxing, and casting of the metal substructure with a thickness of $0.3-0.4 \mathrm{~mm}$. These steps of the sample preparation were performed by experienced restorative consultants (MBS and YAF). Metal frameworks were assessed by means of a sharp-end stainless steel measuring gauge (Patterson Iwanson 
Spring Caliper, Patterson Dental, St. Paul, MN, USA), by an experienced single operator (YAF). Metal frameworks were adjusted to meet the standard thickness (if needed) and returned to the laboratories for porcelain application with shade-mapping (A3.5 cervical 3rd, A2 middle 3rd, and A1 incisal 3rd). The crowns in all labs were fabricated by a representative trained and qualified technician with a minimum of 5 years of professional experience. The final crowns were collected from all laboratories and a code was randomly assigned to each case.

\subsection{Quality Evaluation}

Two experienced clinical restorative consultants (with 10 years of experience, MBS and YAF) using $2.5 \times$ magnification loupes evaluated the quality and shade of each crown anonymously. In the few cases where the examiners assessment was different, a third examiner assessment was performed and the majority decision was adopted (Figure 2A,B). Inter-examiner reliability was assessed with a kappa score of 0.90 .

A

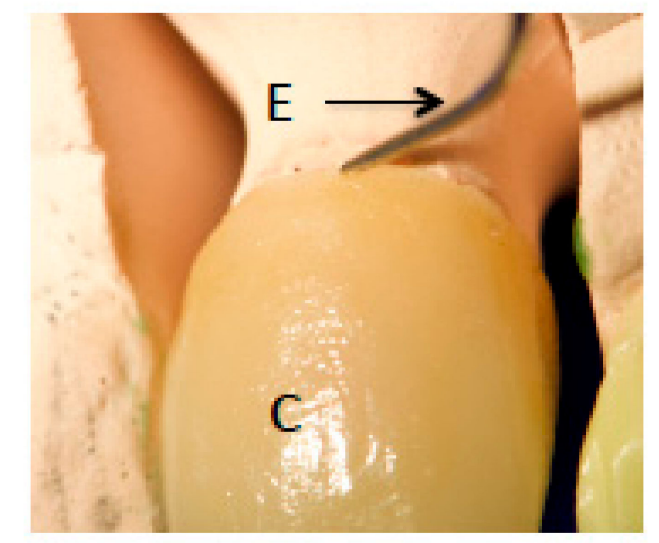

B

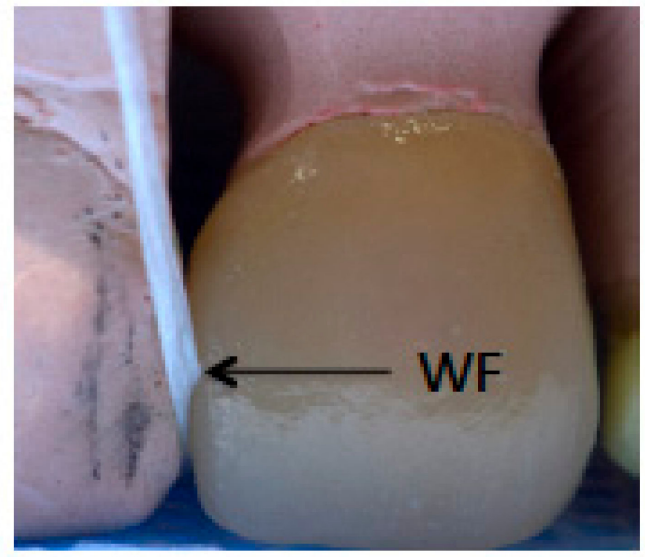

Figure 2. (A) Marginal accuracy assessment of crown (C) with sharp explorer (E). (B) Assessment of contours and contacts with waxed floss (WF).

A sharp new dental explorer (Hu-Friedy Mfg. Co., LLC, Chicago, IL, USA) was used for evaluation of the marginal adaptation. For evaluation of the proximal contacts, waxed dental floss (Oral-B, Procter \& Gamble, Cincinnati, OH, USA) and three different thicknesses $(25,50$, and $100 \mu \mathrm{m})$ of Shim stock aluminum foil (Shim-in-A-Can, DMR, Oakville, ON, Canada) were used. Marginal adaptation, contour, and mesial and distal contact evaluation criteria were performed following the modified United States Public Health Service (USPHS) [22,23] World Dental Federation (FDI) [24] criteria as follows:

\subsubsection{Marginal Adaptation}

R-Excellent/Ideal: Explorer does not catch; continuous adaptation and indistinguishable margins.

S-Acceptable: Explorer detects but cannot penetrate the marginal area.

T-Acceptable with modifications: Detectable and slightly overextended margins.

V-Unacceptable: Gross marginal discrepancies upon explorer examination. Remake is necessary.

\subsubsection{Contour}

$\mathrm{R}$-Excellent/Ideal: Contour follows normal physiologic tooth contour with no adjustments needed.

S-Acceptable: Slightly under- or over-contoured; no modifications needed.

$\mathrm{T}$-Acceptable with modifications: Over-contoured restoration requires re-contouring.

V-Unacceptable: Gross under- or over-contoured crown. Remake is necessary. 


\subsubsection{Proximal Contacts}

$\mathrm{R}$-Excellent/Ideal: Dental floss can be inserted under pressure and/or $25 \mu \mathrm{m}$ (but not $50 \mu \mathrm{m})$ metal matrix can be inserted.

S-Acceptable (light): Dental floss can be inserted with minimal resistance and/or $50 \mu \mathrm{m}$ (but not $100 \mu \mathrm{m}$ ) metal matrix can be inserted.

T-Acceptable with modifications (too strong): Dental floss can be inserted only with pressure and force and/or $25 \mu \mathrm{m}$ metal matrix cannot be inserted. Crown needs adjustment before cementation.

V-Not acceptable (open): Dental floss passes through without any resistance, and/or $100 \mu \mathrm{m}$ metal matrix can be inserted. Crown needs redo.

Readings of the marginal integrity, contour, and mesial and distal contacts were collected and analyzed, and data were analyzed.

A single PFM crown from each laboratory (commercial and government) was evaluated. For marginal assessment, crown contour and proximal contacts, 32, 32, and 64 evaluations in duplicate (two examiners) were performed.

\subsection{Shade Evaluation}

Both visual assessment and digital colorimeter shade evaluations were conducted. The visual shade evaluation included the VITA PAN classic shade guide (H. Rauter GmbH \& Co. Kg, Homberg, Germany). Each clinician evaluated the shade separately (twice), with a 2-week interval between the evaluations. All visual examinations were conducted in the same dental office between 11:00 a.m. and 3:00 p.m by restorative dentistry consultants (MBS and YAF). The shade on which both clinicians agreed was chosen for the cervical, middle, and incisal areas of the crown. Colorimeter readings were performed by means of the ShadeEye-NCC Colorimeter (Shofu Inc., Kyoto, Japan) twice at a 2-week interval. In case of discrepancy in the two readings, a third evaluation was conducted (TJ). A total of 64 visual and 128 colorimeter assessments were performed in total for shade evaluations.

\subsection{Statistical Analysis}

The quantitative data was analyzed using the Statistical Package for the Social Sciences (SPSS, v. 20 for Windows, IBM Statistics Inc., Chicago, IL, USA). Descriptive analysis was performed to present an overview of the findings. Two-way cross-tabulation was used for comparison of proportions for each parameter between government and commercial LABs. Differences between groups were examined by Pearson's Chi-square test and Fisher's exact test for linear trends. A Bonferroni correction was performed due to repeated measurements and a $p$ value of $0.05 / 8=0.0062$ was considered as statistically significant.

\section{Results}

\subsection{Quality}

\subsubsection{Marginal Adaptation}

A majority of the laboratory $(n=22,68.8 \%)$ fabricated crowns showed acceptable marginal adaptation, including $45.5 \%$ government and $54.5 \%$ commercial LABs (Table 1 ). Four commercial LABs only showed excellent margin and adaptation. By contrast, two and four government LABs presented unacceptable and acceptable with modification and marginal adaptation, respectively (Table 1). Commercial LABs exhibited comparable marginal adaptation compared to government LABs ( $p>0.006)$. Overall, $80 \%$ of crowns fabricated by LABs presented excellent or acceptable margin adaptation, with $20 \%$ either requiring modifications or were unacceptable.

\subsubsection{Crown Contours}

Twelve laboratory (37.5\%) fabricated crowns showed excellent contours, including $83.3 \%$ commercial LABs and $16.6 \%$ government LABs (Table 1 ). Regarding acceptable crowns (6 (18.7\%)), 66.6\% were from commercial LABs and 33.3\% were made in government LABs. The acceptable with modifications and unacceptable crowns, fabricated 
by government LABs, were $8(80 \%)$ and $4(100 \%)$, respectively. By contrast, only 2 and 0 crowns in the acceptable with modifications and unacceptable category were made in commercial LABs. Commercial laboratory fabricated crowns showed significantly better contours than government LAB fabricated crowns $(p=0.002)$. Overall, $14(43 \%)$ LABs made crown contours which either required modifications or were unacceptable (Table 1).

Table 1. Comparison of crown marginal adaptation and crown contour quality among different laboratories.

\begin{tabular}{|c|c|c|c|c|}
\hline \multicolumn{5}{|c|}{ Marginal Adaptation } \\
\hline $\begin{array}{c}\text { Quality of Fit } \\
\text { Criteria-Based Evaluation. }\end{array}$ & $\begin{array}{l}\text { Government LABs } \\
\text { (N and Row \%) }\end{array}$ & $\begin{array}{l}\text { Commercial LABs } \\
\text { (N and Row \%) }\end{array}$ & $\begin{array}{c}\text { Total } \\
\text { (N and Column \%) }\end{array}$ & $p$ Value \\
\hline Excellent & $0(0)$ & $4(100)$ & $4(12.5)$ & \multirow{4}{*}{0.007} \\
\hline Acceptable & $10(45.5)$ & $12(54.5)$ & $22(68.8)$ & \\
\hline Acceptable with modifications & $4(100)$ & $0(0)$ & $4(12.5)$ & \\
\hline Unacceptable & $2(100)$ & $0(0)$ & $2(6.20)$ & \\
\hline \multicolumn{5}{|c|}{ Crown Contours } \\
\hline $\begin{array}{c}\text { Quality of Contours } \\
\text { Criteria-Based Evaluation. }\end{array}$ & $\begin{array}{c}\text { Government LABs } \\
\text { (N and Row } \\
\text { Percentage) }\end{array}$ & $\begin{array}{c}\text { Commercial LABs } \\
\text { (N and Row } \\
\text { Percentage) }\end{array}$ & $\begin{array}{c}\text { Total } \\
(\mathrm{N} \text { and Column \%) }\end{array}$ & $p$ Value \\
\hline Excellent & $2(16.6)$ & $10(83.4)$ & $12(37.5)$ & \multirow{4}{*}{0.002} \\
\hline Acceptable & $2(33.4)$ & $4(66.6)$ & $6(18.75)$ & \\
\hline Acceptable with modifications & $8(80)$ & $2(20)$ & $10(31.25)$ & \\
\hline Unacceptable & $4(100)$ & $0(0)$ & $4(12.5)$ & \\
\hline
\end{tabular}

\subsubsection{Proximal Contacts}

Only $25 \%(n=8)$ of all crowns had excellent mesial contacts, including 6 from commercial LABs and 2 from government LABs (Table 2). A majority of LABs $(62.5 \%, \mathrm{n}=20)$ produced crowns acceptable with modifications of mesial contacts, equally distributed between government $(\mathrm{n}=10,50 \%)$ and commercial $(\mathrm{n}=10,50 \%)$ LABs respectively. Overall, $6.2 \%$ of crowns fabricated had unacceptable contacts, and there was no statistical difference in mesial proximal contacts fabricated by commercial and government LABs $(p=0.125)$.

Ten laboratory (31.3\%) fabricated crowns showed excellent distal contacts, including $80 \%$ commercial and $20 \%$ government LABs (Table 2$)$. Half $(n=16)$ of all LAB fabricated crowns had distal contact which was either unacceptable or acceptable with modifications. A total of $75 \%(n=6)$ of the crowns with unacceptable distal contacts were fabricated by government LABs, however only two commercial LABs showed unacceptable distal contacts. Commercial laboratories fabricated crowns with better distal proximal contacts; however, no statistically significant difference was found between the two LAB groups $(p=0.106)$.

\subsection{Shade Matching}

\subsubsection{Visual Assessment}

Overall, $62.5 \%(n=20)$ of the LABs showed shade matching in the cervical third. A total of $75 \%(n=12)$ of the commercial LABs and $50 \%(n=8)$ of the government LABs produced matching shades for cervical thirds of their crowns. However, no statistically significant difference was found between the two LAB groups $(p=0.273)$. For the middle third, $75 \%(n=24)$ of the LABs showed shade matching (Table 3). An equal proportion $(n=12)$ of commercial LABs and government LABs showed successful shade matching. Therefore, no statistically significant difference was found between the tested groups in matching the middle third $(p=1.0)$. In the incisal third, only $43.7 \%(n=14)$ of the LABs showed shade matching (Table 3). Furthermore, $68.7 \%(n=11)$ of commercial LABs and only $18.7 \%(n=3)$ of government LABs succeeded in matching the incisal third shade. 
Fisher's exact test showed a statistically significant difference between government and commercial LABs in the incisal third $(p=0.001)$.

Table 2. Comparison of goodness of mesial and distal proximal contacts among different laboratories.

\begin{tabular}{|c|c|c|c|c|}
\hline \multicolumn{5}{|c|}{ Mesial Proximal Contact } \\
\hline $\begin{array}{c}\text { Quality of Contacts } \\
\text { Criteria-Based Evaluation }\end{array}$ & $\begin{array}{l}\text { Government LABs } \\
(\mathrm{N} \text { and Row \%) }\end{array}$ & $\begin{array}{l}\text { Commercial LABs } \\
\text { (N and Row \%) }\end{array}$ & $\begin{array}{c}\text { Total } \\
(\mathrm{N} \text { and Column \%) }\end{array}$ & $p$ Value \\
\hline Excellent & $2(25)$ & $6(75)$ & $8(25)$ & \multirow{4}{*}{0.125} \\
\hline Acceptable & $2(100)$ & $0(0)$ & $2(6.25)$ & \\
\hline Acceptable with modifications & $10(50)$ & $10(50)$ & $20(62.5)$ & \\
\hline Unacceptable & $2(100)$ & $0(0)$ & $2(6.25)$ & \\
\hline \multicolumn{5}{|c|}{ Distal Proximal Contact } \\
\hline $\begin{array}{l}\text { Quality of Contacts } \\
\text { Criteria-Based Evaluation }\end{array}$ & $\begin{array}{c}\text { Government LABs } \\
\text { (N and Row } \\
\text { Percentage) }\end{array}$ & $\begin{array}{c}\text { Commercial LABs } \\
\text { (N and Row } \\
\text { Percentage) }\end{array}$ & $\begin{array}{c}\text { Total } \\
\text { (N and Column \%) }\end{array}$ & $p$ Value \\
\hline Excellent & $2(20)$ & $8(80)$ & $10(31.3)$ & \multirow{4}{*}{0.106} \\
\hline Acceptable & $4(66.6)$ & $2(33.4)$ & $6(18.7)$ & \\
\hline Acceptable with modifications & $4(50)$ & $4(50)$ & $8(25)$ & \\
\hline Unacceptable & $6(75)$ & $2(25)$ & $8(25)$ & \\
\hline
\end{tabular}

Table 3. Comparison of visual shade matching overall and among different thirds of PFM (porcelain fused to metal) crowns fabricated by different laboratories.

\begin{tabular}{|c|c|c|c|c|}
\hline \multicolumn{5}{|c|}{ Visual Shade Matching, Cervical 3rd } \\
\hline $\begin{array}{c}\text { Accuracy of Shade, } \\
\text { Criteria-Based Evaluation. }\end{array}$ & $\begin{array}{l}\text { Government LABs } \\
\text { (N and Row \%) }\end{array}$ & $\begin{array}{l}\text { Commercial LABs } \\
\text { (N and Row \%) }\end{array}$ & $\begin{array}{c}\text { Total } \\
\text { (N and Column \%) }\end{array}$ & $p$ Value \\
\hline Matching & $8(40)$ & $12(60)$ & $20(62.5)$ & \multirow{2}{*}{0.273} \\
\hline Non-Matching & $8(66.6)$ & $4(33.4)$ & $12(37.5)$ & \\
\hline \multicolumn{5}{|c|}{ Visual Shade Matching, Middle Third } \\
\hline Matching & $12(50)$ & $12(50)$ & $24(75)$ & \multirow{2}{*}{1.0} \\
\hline Non-Matching & $4(50)$ & $4(50)$ & $8(25)$ & \\
\hline \multicolumn{5}{|c|}{ Visual Shade Matching, Incisal Thid } \\
\hline Matching & $3(21.5)$ & $11(78.5)$ & $14(43.7)$ & \multirow{2}{*}{0.004} \\
\hline Non-Matching & $13(72.3)$ & $5(27.7)$ & $18(56.3)$ & \\
\hline \multicolumn{5}{|c|}{ Overall Visual Shade Matching (All Thirds) } \\
\hline Complete Matching & $1(12.5)$ & $7(87.5)$ & $8(25)$ & \multirow{4}{*}{0.005} \\
\hline 2/3rd matching & $11(61.2)$ & $7(38.8)$ & $18(56.25)$ & \\
\hline 1/3rd matching & $0(0)$ & $2(100)$ & $2(6.25)$ & \\
\hline None matching & $4(100)$ & $0(0)$ & $4(12.5)$ & \\
\hline
\end{tabular}

The number of crown thirds that were successfully matched by each LAB category is shown in Table 3. Nearly $44 \%(n=7)$ of the commercial LABs and $6.2 \%(n=1)$ of government LABs perfectly matched all three thirds. Overall, commercial LABs produced PFM crowns with significantly better visual shade matching than government LABs $(p=0.004)$.

\subsubsection{ShadeEye Assessment}

Table 4 presents the ShadeEye color matching outcomes among the LAB groups. We found that $62.5 \%$ of all LABs produced crowns with matching shades, including $8(40 \%)$ 
government LABs and $12(60 \%)$ commercial LABs. A total of 50\% $(n=8)$ of the government LABs and $75 \%(n=12)$ of the commercial LABs matched the cervical third in their crowns. Furthermore, $50 \%$ of government LABs and $25 \%$ of commercial LABs failed to match crown shade. Fisher's exact test showed no statistically significant difference between government and commercial LABs in the cervical third $(p=0.273)$. In the middle third, $84 \%$ of crowns were shade matched, including $51 \%$ government and $48 \%$ commercial LABs. About $81 \%(n=13)$ of commercial LABs and $87.5 \%(n=14)$ of government LABs showed shade matching in the middle third (Table 4). Statistically, both LAB types showed similar accuracy of shade matching in the middle third $(p=1.0)$.

Table 4. Comparison of ShadeEye color matching overall and among different thirds of PFM crowns fabricated by different laboratories.

\begin{tabular}{|c|c|c|c|c|}
\hline \multicolumn{5}{|c|}{ ShadeEye Shade Matching, Cervical Third } \\
\hline $\begin{array}{c}\text { Accuracy of Shade, } \\
\text { Criteria-Based Evaluation. }\end{array}$ & $\begin{array}{l}\text { Government LABs } \\
\text { (N and Row \%) }\end{array}$ & $\begin{array}{l}\text { Commercial LABs } \\
\text { (N and Row \%) }\end{array}$ & $\begin{array}{c}\text { Total } \\
\text { (N and Column \%) }\end{array}$ & $p$ Value \\
\hline Matching & $8(40)$ & $12(60)$ & $20(62.5)$ & \multirow{2}{*}{0.27} \\
\hline Non-Matching & $8(66.6)$ & $4(33.3)$ & $12(37.5)$ & \\
\hline \multicolumn{5}{|c|}{ ShadeEye Shade Matching, Middle Third } \\
\hline Matching & $14(51.8)$ & $13(48.1)$ & $27(84.4)$ & \multirow{2}{*}{1.0} \\
\hline Non-Matching & $2(40)$ & $3(60)$ & $5(15.6)$ & \\
\hline \multicolumn{5}{|c|}{ ShadeEye Shade Matching, Incisal Third } \\
\hline Matching & $2(16.6)$ & $10(83.3)$ & $12(37.5)$ & \multirow{2}{*}{0.004} \\
\hline Non-Matching & $14(70)$ & $6(30)$ & $20(62.5)$ & \\
\hline \multicolumn{5}{|c|}{ Overall ShadeEye Shade Matching (All Thirds) } \\
\hline Complete Matching & $0(0)$ & $8(100)$ & $8(25)$ & \multirow{4}{*}{0.001} \\
\hline 2/3rd matching & $10(83.4)$ & $2(16.6)$ & $12(37.5)$ & \\
\hline $1 / 3$ rd matching & $4(40)$ & $6(60)$ & $10(31.3)$ & \\
\hline None matching & $2(100)$ & $0(0)$ & $2(6.2)$ & \\
\hline
\end{tabular}

A mere $37.5 \%$ of LABs showed shade matching in the incisal third, including $10(83 \%)$ commercial and only $2(16.6 \%)$ government LABs. A staggering $87.5 \%(n=14)$ of government LABs failed to match shades in the incisal third. A total of $62.5 \%(\mathrm{n}=10)$ of commercial LABs were able to produce PFM crowns with accuracy of color. The overall ability of government LABs to produce color-matching crowns was significantly lower than commercial LABs $(p=0.001)$.

\section{Discussion}

This comparative study aimed to evaluate the performance of different prosthetic LABs in the production of high-quality and esthetic PFM crowns. It was based on the hypothesis that there is no significant difference among laboratories (government and commercial) in marginal adaptation, contours, contacts, and shade matching of PFM crowns. It was observed that contours and color matching of PFM crowns was significantly different $(p<0.006)$, and government LABs showed poor outcomes compared to commercial LABs. Therefore the hypothesis was rejected. A myriad of explanations are presented for the observed findings, including study methodology, ceramic materials, work environment, technical skills, and quality management.

PFM crowns are the most commonly used prosthetic restoration in dentistry [14]. For a successful PFM crown to be produced, careful diagnosis and clinical management of the case, as well as the choice of a good laboratory, are important factors. Dental laboratories differ in their abilities to acquire good equipment with high-quality materials, 
or to hire skillful technicians, which may affect the prosthesis from these LABs. In the present study, evaluations of quality were performed according to modified USPHS/FDI criteria. The original USPHS criteria did not include proximal contact assessment $[22,23]$. Therefore, the FDI criteria were also included for the evaluation of interproximal contacts. Previous studies have validated the application of these criteria for chair-side reproducible assessments of direct and indirect dental restorations [25-27]. In addition, to evaluate marginal integrity, a sharp dental explorer is considered to be a reliable clinical tool for the detection of marginal gaps [28,29]. Moreover, studies have used dental floss for the evaluation of proximal contacts for both direct and indirect restorations [30,31]. However, it is recommended to use metal strips with specific thicknesses for more reliable results [23,32-34]. In the present study, both methods were used and integrated in the evaluation criteria, and the relationship of the tinfoil thickness to the resistance of dental floss was tested and verified in all cases. The use of a master cast to evaluate the crowns with adjacent teeth that are fixed and immobile, in contrast to the natural teeth that were examined in the other studies, can also explain these results [32-34].

In this study, commercial laboratories performed better than government laboratories in the fabrication of PFM crowns (contours and shade matching). Although the percentage of unacceptable PFM crowns from both types of laboratories was low, a difference between the two laboratory types was not present. Previous studies have reported similar outcomes [21]. In the study by Alshiddi et al., margins of the crowns fabricated by commercial LABs were not statistically different to the crowns made by dental school laboratories [34]. This is in line with the findings of the present study.

Interestingly, PFM crown shades were assessed visually and digitally (by means of a colorimeter), since these two methods are considered to be the most commonly used tooth color measuring techniques [35]. In addition, Vita TM classic has been documented as the most commonly used shade guide [36]. Although the traditional clinical method used for evaluating shades is a visual comparison of the tooth or the restoration with commercial shade guides [37], possible limitations, including the subjectivity of color perception between and among individuals, eye fatigue and color deficiencies [37], mandated the use of an adjunct method to evaluate crown shades. In the present study, three sites were measured in each crown; therefore, ShadeEye-NCC was used as the adjunct measuring tool, having a smaller terminal measuring tip with a diameter of $2.5 \mathrm{~mm}$. It has been documented that visual shade confirmation is recommended when the ShadeEye-NCC colorimeter is used [38].

In the present study, visual shade assessments exhibited better performance of all LABs in the middle thirds, followed by cervical thirds. The worst shade matching results were reported in the incisal thirds. Although commercial LABs performed better than or equal to government LABs in all thirds, differences among the two lab groups were not significant in cervical and middle thirds. In the incisal third, however, the results were significantly different between the tested groups. These results were confirmed by the colorimeter readings; however, for the middle thirds, 14 government LABs matched the shade compared with 13 commercial LABs. The inferior performance of the LABs, especially in matching the incisal thirds, is attributed to the translucency and thickness of porcelain in this area, the variations in the veneering ceramics, the difference in illumination in LABs, experience of LAB technicians, and the work ethics in different LABs. Findings for the visual and colorimeter readings in this study were identical in the cervical thirds. However, for the middle and incisal thirds, small differences between the two methods were reported. Since ShadeEye-NCC is designed with a flat detecting tip, for the measurement of surfaces, it is prone to edge-loss effects, which may lead to incorrect readings. These findings were also reported by Yuan et al. [38]. For accurate matching of crown shades in all thirds, both test methods confirmed the significant superior performance of commercial LABs compared with government LABs.

The outcomes of the study should be interpreted in light of the possible limitations. Only one representative specimen from each LAB was used for evaluations and this 
could result in under- or over-expressing the disparity among LABs. In addition, dental LABs produce multiple types of prostheses including orthodontic appliances, crowns, fixed partial dentures, removable dentures, trays, stents, and maxillofacial prostheses. However, the present study assessed a simple and most commonly fabricated prosthesis (PFM crown) to represent the work of LABs. These simplifications due to methodological restrictions suggest that the quality and accuracy findings should not be applicable to other LAB products and are limited to PFM crowns. The outcomes of this study highlight the disparity of prosthesis quality fabricated by different technicians and LABs. In addition, as outcomes of dental restorative treatments are directly dependent on restoration quality, it is critical to comprehend that improving the quality of LABs and technician skills will improve the quality of dental care in the community. This inconsistency in quality among LABs is attributed to the experience, training and skill of technicians, management of quality control, and working environment at the LABs. It is also observed that technicians are working longer hours in a challenging, performance- and incentive-based setting in commercial LABs, referred to as perform or perish. However, government setting, although allowing for better training and skill development, may be less challenging and the performance is not incentive based. As factors influencing the variation in outcomes of LABs are not investigated, further studies are recommended in this regard. Moreover, to increase the quality of dental health among the population, in line with the established standards, updating the knowledge and skills of technicians should be prioritized and a robust quality assessment and feedback process implemented.

\section{Conclusions}

Overall, the proximal contacts and marginal adaptation of PFM crowns fabricated by commercial and government managed LABs were comparable. However, contours and color matching of PFM crowns produced by commercial LABs were significantly better compared to government LABs.

Author Contributions: M.S.B.-S. and Y.F.A.: Data collection, study design, data assessment, and manuscript writing, final manuscript approval and manuscript writing. H.A.A. and A.S.A.: Data inference, data collection, study design, manuscript drafting, data analysis, and manuscript approval. I.B.A. and K.M.A.: Data interpretation, Data collection, funding, resources, data interpretation, writing, revise, and editing and final manuscript approval. B.A., F.V. and T.A.: Data analysis, Data collection, data interpretation, funding, resources, software, writing, revise, and editing and final manuscript approval. E.A.A.: Data analysis, statistics, resources, manuscript review/revisions, validation, visualization. All authors have read and agreed to the published version of the manuscript.

Funding: The authors are grateful to the Deanship of Scientific Research, King Saud University for funding through Vice Deanship of Scientific Research Chairs, Research Chair for Biological Research in Dental Health.

Institutional Review Board Statement: The study was laboratory based assessed of ceramic crowsn. This study did not included individuals patients information or human tissue or any contact with patients. Therefore the study did not require ethical approval.

Informed Consent Statement: As not patient contact was involved in the study. And there was no human or other tissue involved in the study, no consent was taken from patients.

Data Availability Statement: The data presented in this study are available on request from the corresponding author.

Acknowledgments: The authors are grateful to the Deanship of Scientific Research, King Saud University for funding through Vice Deanship of Scientific Research Chairs, Research Chair for Biological Research in Dental Health.

Conflicts of Interest: The authors declare that they have no conflict of interest and all authors have read and approved the final draft. 


\section{References}

1. McCracken, M.S.; Litaker, M.S.; Gordan, V.V.; Karr, T.; Sowell, E.; Gilbert, G.H.; National Dental PBRN Collaborative Group. Remake Rates for Single-Unit Crowns in Clinical Practice: Findings from the National Dental Practice-Based Research Network. J. Prosthodont. 2019, 28, 122-130. [CrossRef] [PubMed]

2. Farah, J.W.; Dootz, E.; Mora, G.; Gregory, W. Insights of dental technicians: A survey of business and laboratory relations with dentists. Dentistry 1991, 11, 9. [PubMed]

3. Bin-Shuwaish, M.S. Compliance of dental laboratory technicians with dentists' instructions for fabrication of a PFM crown. Saudi J. Dent. Res. 2017, 8, 35-41. [CrossRef]

4. Afsharzand, Z.; Rashedi, B.; Petropoulos, V.C. Communication between the dental laboratory technician and dentist. Work authorization for fixed partial dentures. J. Prosthodont. 2006, 15, 123-128. [CrossRef] [PubMed]

5. Leeper, S.H. Dentist and laboratory: A “love-hate” relationship. Dent. Clin. N. Am. 1979, 23, 87-99. [PubMed]

6. Barsby, M.J.; Johnson, A.; Welfare, R.D.; Winstanley, R.B. Guides to Standards in Prosthetic Dentistry-Complete and Partial Dentures; British Society for the Study of Prosthetic Dentistry: London, UK, 2005.

7. Almohareb, T.; Alkatheeri, M.S.; Vohra, F.; Alrahlah, A. Influence of experimental staining on the color stability of indirect computer-aided design/computer-aided manufacturing dental provisional materials. Eur. J. Dent. 2018, 12, 269-274. [CrossRef] [PubMed]

8. Vohra, F.; Labban, N.; Al-Hussaini, A.; Al-Jarboua, M.; Zawawi, R.; Alrahlah, A.; Naseem, M. Influence of Er; Cr: YSGG Laser on Shear Bond Strength and Color Stability of Lithium Disilicate Ceramics: An In Vitro Study. Photobiomodulation Photomed. Laser Surg. 2019, 37, 483-488. [CrossRef]

9. Samer, M.S.; Faraz, Q.; Al-Dubai, S.A.; Vohra, F.; Abdullah, H.; Taiyeb-Ali, T.B.; Saub, R. Clinical outcomes and predictors of satisfaction in patients with improved lithium disilicate all-ceramic crowns. Med. Princ. Pract. 2017, 26, 470-479. [CrossRef]

10. Vohra, F.; Altwaim, M.; Alshuwaier, A.S.; Alomayri, A.; Al-Deeb, M.; AlFawaz, Y.F.; Alrabiah, M.; Al-Ahdal, K.; Al-Deeb, L.; Abduljab-bar, T. Bond integrity and microleakage of dentin-bonded crowns cemented with bioactive cement in comparison to resin cements: In vitro study. J. Appl. Biomater. Funct. Mater. 2020, 18, 2280800020905768. [CrossRef]

11. Al-Aali, K.A.; Alhamdan, R.S.; Maawadh, A.M.; Vohra, F.; Abduljabbar, T. Influence of contemporary CAD-CAM milling systems on the fit and adaptation of partially stabilized Zirconia fixed partial dentures. Pak. J. Med. Sci. 2020, 37, 45-51. [CrossRef] [PubMed]

12. Vohra, F.; Altwaim, M.; Alshuwaier, A.S.; Al-Deeb, M.; Alfawaz, Y.; Alrabiah, M.; Abduljabbar, T. Influence of Bioactive, Resin and Glass Ionomer luting cements on the fracture loads of dentin bonded ceramic crowns. Pak. J. Med. Sci. 2020, 36, $416-421$. [CrossRef] [PubMed]

13. Van der Burgt, T.P.; Ten Bosch, J.J.; Borsboom, P.C.; Kortsmit, W.J. A comparison of new and conventional methods for quantification of tooth color. J. Prosthet. Dent. 1990, 63, 155-162. [CrossRef]

14. Behr, M.; Zeman, F.; Baitinger, T.; Galler, J.; Koller, M.; Handel, G.; Rosentritt, M. The clinical performance of porcelain-fused-tometal precious alloy single crowns: Chipping, recurrent caries, periodontitis, and loss of retention. Int. J. Prosthodont. 2014, 27, 153-160. [CrossRef] [PubMed]

15. Seghi, R.; Johnston, W.; O’Brien, W. Spectrophotometric analysis of color differences between porcelain systems. J. Prosthet. Dent. 1986, 56, 35-40. [CrossRef]

16. Chiche, G.J.; Pinault, A. Esthetics of Anterior Fixed Prosthodontics; Quintessence: Chicago, IL, USA, 1994; pp. 61-64.

17. White, J.; O'Brien, W. The Colors of Mixtures of Dental Opaque Porcelains. J. Dent. Res. 1989, 68, 1319-1322. [CrossRef]

18. Reyes, J.; Acosta, P.; Ventura, D. Repeatability of the human eye compared to an intraoral scanner in dental shade matching. Heliyon 2019, 5, e02100. [CrossRef]

19. Yilmaz, B.; Karaagaclioglu, L. In vitro evaluation of color replication of metal ceramic specimens using visual and instrumental color determinations. J. Prosthet. Dent. 2011, 105, 21-27. [CrossRef]

20. Jathmi, A.A.A.; Alqahtani, M.A.A.; Hussain, M.W. Evaluation of accuracy of shade selection ability of students in the dental clinics and duplication of selected shade by the dental laboratory. A spectrophotometric in-vivo study. Saudi Dent. J. 2019,31, S77. [CrossRef]

21. Alshiddi, I.F.; Habib, S.R.; Al-Mazrou, F.Y.; Aly, A.M.; Al-Zaid, A.M. Comparing government (school) vs. private (non-school) dental laboratories in marginal adaptation of single porcelain-fused-to-metal crowns. Oral Health Dent. Manag. 2014, 13, 707-711.

22. Cvar, J.F.; Ryge, G. Reprint of Criteria for the clinical evaluation of dental restorative materials. Clin. Oral Investig. 2006, 10, 92. [CrossRef]

23. Bayne, S.C.; Schmalz, G. Reprinting the classic article on USPHS evaluation methods for measuring the clinical research performance of restorative materials. Clin. Oral Investig. 2005, 9, 209-214. [CrossRef] [PubMed]

24. Hickel, R.; Peschke, A.; Tyas, M.; Mjör, I.; Bayne, S.; Peters, M.; Hiller, K.A.; Randall, R.; Vanherle, G.; Heintze, S.D. FDI World Dental Federation: Clinical criteria for the evaluation of direct and indirect restorations-Update and clinical examples. Clin. Oral Investig. 2010, 14, 349-366. [CrossRef]

25. Marquillier, T.; Doméjean, S.; le Clerc, J.; Chemla, F.; Gritsch, K.; Maurin, J.-C.; Millet, P.; Pérard, M.; Grosgogeat, B.; Dursun, E. The use of FDI criteria in clinical trials on direct dental restorations: A scoping review. J. Dent. 2018, 68, 1-9. [CrossRef] 
26. Selz, C.F.; Strub, J.R.; Vach, K.; Guess, P.C. Long-term performance of posterior InCeram Alumina crowns cemented with different luting agents: A prospective, randomized clinical split-mouth study over 5 years. Clin. Oral Investig. 2014, 18, 1695-1703. [CrossRef] [PubMed]

27. Batson, E.R.; Cooper, L.F.; Duqum, I.; Mendonça, G. Clinical outcomes of three different crown systems with CAD/CAM technology. J. Prosthet. Dent. 2014, 112, 770-777. [CrossRef]

28. Baldissara, P.; Baldissara, S.; Scotti, R. Reliability of tactile perception using sharp and dull explorers in marginal opening identification. Int. J. Prosthodont. 1998, 11, 591-594.

29. Hayashi, M.; Wilson, N.H.; Ebisu, S.; Watts, D.C. Influence of explorer tip diameter in identifying restoration margin discrepancies. J. Dent. 2005, 33, 669-674. [CrossRef]

30. Teich, S.T.; Joseph, J.; Sartori, N.; Heima, M.; Duarte, S. Dental floss selection and its impact on evaluation of interproximal contacts in licensure exams. J. Dent. Educ. 2014, 78, 921-926. [CrossRef] [PubMed]

31. Prakki, A.; Cilli, R.; Saad, J.O.C.; Rodrigues, J.R. Clinical evaluation of proximal contacts of Class II esthetic direct restorations. Quintessence Int. 2004, 35, 785-789.

32. Boice, P.A.; Niles, S.M.; Dubois, L.M. Evaluation of proximal contacts with shim stock. J. Oral Rehabil. 1987, 14, 91-94. [CrossRef]

33. Dubois, L.M.; Niles, S.M.; Boice, P.A. The magnitude of interproximal spaces between adjacent teeth. Am. J. Dent. 1993, 6, 315-317. [CrossRef] [PubMed]

34. Kim, K.-H.; Jung, J.-H.; Kim, H.-J.; Chung, C.-H.; Oh, S.-H. Evaluation of tightness of proximal tooth contact in permanent dentition. J. Korean Acad. Prosthodont. 2008, 46, 553-560. [CrossRef]

35. Chen, H.; Huang, J.; Dong, X.; Qian, J.; He, J.; Qu, X.; Lu, E. A systematic review of visual and instrumental measurements for tooth shade matching. Quintessence Int. 2012, 43, 649-659.

36. Brewer, J.D.; Wee, A.; Seghi, R. Advances in color matching. Dent. Clin. N. Am. 2004, 48, 341-358. [CrossRef] [PubMed]

37. Okubo, S.R.; Kanawati, A.; Richards, M.W.; Childressd, S. Evaluation of visual and instrument shade matching. J. Prosthet. Dent. 1998, 80, 642-648. [CrossRef]

38. Yuan, K.; Sun, X.; Wang, F.; Wang, H.; Chen, J.-H. In Vitro and In Vivo Evaluations of Three Computer-Aided Shade Matching Instruments. Oper. Dent. 2012, 37, 219-227. [CrossRef] [PubMed] 